\title{
Phenotype-genotype spectrum of AAA syndrome from Western India and systematic review of literature
}

\author{
Hiren Patt ${ }^{1}$, Katrin Koehler ${ }^{2}$, Sailesh Lodha ${ }^{3}$, Swati Jadhav' ${ }^{1}$, Chaitanya Yerawar', \\ Angela Huebner', Kunal Thakkar', Sneha Arya', Sandhya Nair', \\ Manjunath Goroshi', Hosahithlu Ganesh", Vijaya Sarathi', Anurag Lila', \\ Tushar Bandgar ${ }^{1}$ and Nalini Shah'
}

'Department of Endocrinology, Seth G.S. Medical College \& KEM Hospital, Mumbai, Maharashtra, India ${ }^{2}$ Department of Paediatrics, University Hospital Carl Gustav Carus, Technische Universität Dresden, Dresden, Germany ${ }^{3}$ Eternal Hospital, Jaipur, Rajasthan, India

${ }^{4}$ Department of Endocrinology, AJ Institute of Medical sciences, Mangalore, India

${ }^{5}$ Department of Endocrinology, Vydehi Institute of Medical Sciences and Research Center, Bengaluru, India

Correspondence should be addressed to S Jadhav Email drswatijadhav1980@gmail. com

\begin{abstract}
Objective: To study genotype-phenotype spectrum of triple A syndrome (TAS). Methods: Retrospective chart analysis of Indian TAS patients (cohort 1, $n=8$ ) and review of genotyped TAS cases reported in world literature (cohort 2, $n=133,68$ publications). Results: Median age at presentation was 4.75 years (range: $4-10$ ) and 5 years (range: 1-42) for cohorts 1 and 2, respectively. Alacrima, adrenal insufficiency (AI), achalasia and neurological dysfunction (ND) were seen in $8 / 8,8 / 8,7 / 8$ and $4 / 8$ patients in cohort 1, and in 99, 91, 93 and $79 \%$ patients in cohort 2, respectively. In both cohorts, alacrima was present since birth while Al and achalasia manifested before ND. Mineralocorticoid deficiency (MC) was uncommon (absent in cohort 1, 12.5\% in cohort 2). In cohort 1, splice-site mutation in exon 1 (p.G14Vfs*45) was commonest, followed by a deletion in exon 8 (p.S255Vfs*36). Out of 65 mutations in cohort 2, 14 were recurrent and five exhibited regional clustering. Al was more prevalent, more often a presenting feature, and was diagnosed at younger age in T group (those with truncating mutations) as compared to NT (non-truncating mutations) group. ND was more prevalent, more common a presenting feature, with later age at onset in NT as compared to T group. Conclusion: Clinical profile of our patients is similar to that of patients worldwide. Alacrima is the earliest and most consistent finding. MC deficiency is uncommon. Some recurrent mutations show regional clustering. p.G14Vfs*45 and p.S255Vfs*36 account for majority of AAAS mutations in our cohort. Phenotype of T group differs from that of NT group and merits future research.
\end{abstract}

\author{
Key Words \\ - Allgrove syndrome \\ - triple A syndrome \\ - primary adrenal \\ insufficiency \\ - ALADIN \\ - AAAS gene
}

\section{Introduction}

Triple A syndrome (TAS, MIM \#231550) or Allgrove's syndrome is an autosomal recessive disorder, characterized by clinical triad of alacrima, adrenal insufficiency (AI) and achalasia cardia. TAS patients may have varied neurological dysfunction (ND) in the form of distal sensory motor polyneuropathy, autonomic dysfunction, dementia, mental retardation, bulbospinal amyotrophy, optic atrophy, parkinsonian features, dysarthria, dystonia and chorea (1). Other features described in TAS include microcephaly, short stature, dysmorphic facies with long
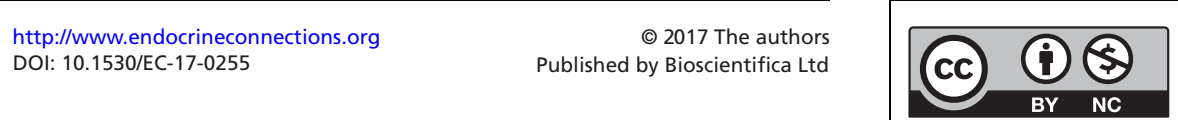

This work is licensed under a Creative Commons Attribution-NonCommercial 4.0 International License. 
narrow face, long philtrum, down-turned mouth, thin upper lip, lack of eyelashes, poor wound healing, palmar and plantar hyperkeratosis, scoliosis, osteoporosis, long QT syndrome and hypolipoproteinemia type IIb (2).

Long time after the initial description of TAS, two groups independently described AAAS (achalasiaaddisonianism-alacrimia syndrome) gene as the causative gene for this syndrome, in years 2000 and 2001, respectively $(3,4,5)$. AAAS gene is located on chromosome $12 \mathrm{q} 13$ and encodes for ALADIN (alacrima, achalasia, adrenal insufficiency, neurologic disorder) protein, a member of WD (tryptophan-aspartic acid) repeat containing proteins' family, which localizes to nuclear pore complexes (NPC). Although exact pathophysiology remains to be elucidated, it is proposed that mutant ALADIN proteins impair the nucleocytoplasmic shuttling of multi-molecular complexes and make the cells susceptible to oxidative stress, resulting in selective tissue degeneration (6).

Given the rarity of this syndrome, literature related to it is confined to case reports/series, which limits comprehensive understanding of its complete spectrum, especially the genotype-phenotype correlation. Herein, we present our series of eight TAS patients from Western India. Additionally, we did systematic review of the published literature, with the aim of analyzing phenotypic and genotypic spectrum of TAS patients worldwide.

\section{Patients and methods}

\section{Cohort 1}

A retrospective clinical case records study of TAS patients (cohort 1) managed at a tertiary care center (2004-2016) in Western India was conducted after obtaining approval from 'Institutional Ethics Committee II, Seth G S Medical College and KEM Hospital, Mumbai'. Waiver of patients' consent was obtained for this retrospective analysis, though due informed consent had been obtained from patients/parents for the genetic analysis. Clinical diagnosis of TAS was based on the presence of a minimum of two features of the triad. Absence of tears was enquired on history, and wherever possible, diagnosis was confirmed by positive Schirmer's test, which was defined as $<10 \mathrm{~mm}$ of moisture on a filter paper, placed under the lower eyelids for 5 minutes. Symptoms suggestive of achalasia were enquired on history, and diagnosis was confirmed by a barium swallow study and/or esophageal manometry.

Biochemical diagnosis of AI was based on 08:00 h serum cortisol $(<5 \mu \mathrm{g} / \mathrm{dL})$ with a simultaneously elevated plasma adrenocorticotropic hormone (ACTH) (>2-fold above the upper limit of the reference interval for the specific assay) (7). Mineralocorticoid (MC) deficiency was defined as elevated (>upper limit of normal for age) plasma renin activity (PRA) level. Serum cortisol was measured by a solid-phase competitive chemiluminescent enzyme immunoassay (Siemens Healthcare) with an analytical sensitivity of $0.2 \mu \mathrm{g} / \mathrm{dL}$. The intra- and interassay coefficients of variability (CVs) of the cortisol assay were $6.9 \%$ and $7.3 \%$, respectively. ACTH was measured by a solid-phase, 2-site sequential chemiluminescent enzyme assay (Siemens Healthcare). The intra- and interassay CVs were $9.6 \%$ and $8.8 \%$, respectively, with an analytical sensitivity of $9 \mathrm{pg} / \mathrm{mL}$. PRA was measured by radio immunoassay (Diasorin, Stillwater, MN, USA). Intraand inter-assay CV were $<0.7 \%$ and $<10 \%$, respectively, with an analytical sensitivity of $0.018 \mathrm{ng} / \mathrm{mL} / \mathrm{h}$.

For genetic testing (AAAS gene), genomic DNA was extracted using a standard protocol. AAAS gene (OMIM*605378, ENST00000209873) was studied by amplification of all 16 exons, including exon-intron boundaries from genomic DNA. After PCR amplification, direct sequencing of the amplicons was carried out using Big Dye Terminator v1.1 Cycle Sequencing kit with an ABI 3100 Genetic Analyzer (Applied Biosystems). The description of sequence variants in DNA and protein sequences were expressed according to the nomenclature of human genome variation society. In silico prediction tools including Mutation Taster, PolyPhen-2 and Sort Intolerant from Tolerant (SIFT) were used to predict the functional significance of variation in sequence.

\section{Cohort 2}

Systematic review of published literature (up to February 2016) was done on MEDLINE and Scopus search engines employing following search terms: TAS, Allgrove syndrome, 3A syndrome, 4A syndrome, 5A syndrome, ALADIN protein and $A A A S$ gene. Initial search revealed 277 publications related to TAS of which 209 publications were excluded for various reasons. Two hundred and two publications were excluded due to lack of genotypic details. Two non-English language papers and two papers describing previously reported patients (to avoid duplication) were also excluded. Additionally, three papers describing summary statistics were excluded, as no clear information about phenotypic and genotypic characteristics of individual patients could be discerned. Finally, data of 133 index cases (cohort 2) from 68 publications were analyzed $(4,5,6,8,9,10,11,12,13$,

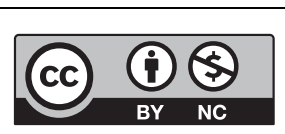

This work is licensed under a Creative Commons Attribution-NonCommercial 4.0 International License. 
$14,15,16,17,18,19,20,21,22,23,24,25,26,27,28,29$, $30,31,32,33,34,35,36,37,38,39,40,41,42,43,44,45$, $46,47,48,49,50,51,52,53,54,55,56,57,58,59,60$, $61,62,63,64,65,66,67,68,69,70,71,72)$. Following information about the phenotype was recorded: gender, age at presentation, age at last follow-up, presenting feature, family history, parental consanguinity, country/ ethnicity of origin, age at onset/diagnosis for each of the key features; alacrima, achalasia, AI and ND and presence of skin manifestations. Wherever available, relevant biochemical investigations like basal serum cortisol and ACTH levels, results of ACTH stimulation test, PRA levels and plasma aldosterone levels were also recorded. To maintain uniformity of genetic data, the reported mutations were re-annotated using the university of California Santa Cruz (UCSC) genome browser according to the transcript id ENST00000209873. Exome Aggregation Consortium (ExAC database) was used to find the minor allele frequency (MAF) of the mutation identified.

\section{Statistical analysis}

Statistical analysis was performed using software SPSS, version 23.0 (SPSS Software). Mean ( \pm s.D.) was used for continuous variables when they were normally distributed and median (range) was used for variables with skewed distribution. The difference between the continuous variables was analyzed using independent $t$ test while that between categorical variables was analyzed using chi-square test. $P$ value $<0.05$ was considered as significant.

\section{Results}

\section{Phenotype (cohort 1)}

Cohort 1 comprises 8 index TAS patients ( 3 males, 5 females) managed at our center. The clinical details are summarized in Supplementary Table 1 (see section on supplementary data given at the end of this article). Median age at last follow-up was 17.5 years (range 5.5-28). By then, all patients had manifested three classic components of the triad (alacrima, achalasia and AI), except for one patient (patient 8), who has not yet developed symptoms of achalasia at current age of 5.5 years. Alacrima and AI were present in all $(8 / 8)$ patients, while achalasia and ND were seen in $7 / 8$ and $4 / 8$ patients, respectively. Median age at presentation was 4.7 years (range: $4-10$ years). All patients presented with AI except one patient (patient 6). Patient 6 had presented with ocular discomfort due to alacrima at
5 years of age, though diagnosis of AS was not considered at that time. In all patients, alacrima was the earliest feature noted by parents in early infancy. It was followed by AI with median age at onset of 3.25 years (range: 2.5-10), and achalasia with median age of onset of 14 years (range: 3-20 years). All patients had clinically evident AI with low basal cortisol and elevated ACTH, and none required Synacthen stimulation test for diagnosis. All had normal mineralocorticoid axis as demonstrated by normal PRA levels. Three patients have undergone per oral endoscopic myotomy for severe symptoms of dysphagia and one patient (patient 6) is currently awaiting the procedure. Other patients have mild symptoms of dysphagia and are being managed conservatively. ND was found in 4 patients (50\%) after a thorough history and clinical neurological examination. Detailed nerve conduction studies were not done in all patients. The ND in our cohort included generalized tonic-clonic seizure disorder $(n=2)$, moderate mental subnormality (documented by IQ test) $(n=1)$, generalized hyper-reflexia $(n=4)$ and hypernasal speech $(n=3)$. Two patients had palmoplantar hyperkeratosis.

\section{Genotype (cohort 1)}

Four patients (4/8) had history of other family members being similarly affected. Two of them had parental consanguinity as well (Fig. 1 and Supplementary Table 1). Genotype analysis of these eight unrelated families revealed five different mutations (novel: 1, reported: 4) in $A A A S$ gene (Fig. 1). Five patients had mutations in homozygous state, two patients in compound heterozygous state while one patient (patient 8) was heterozygous for a novel mutation (Supplementary Table 1). A previously reported frameshift mutation in exon 1 (c.43C>A, p.G14Vfs*45) was the commonest mutation, observed in four families. A deletion in exon 8 (c.762delC; p.S255Vfs*36) was the next common mutation, found in three families. Previously reported mutations in exon 16 (c.1432C >T; p.R478*), exon 9 (c.856C>T, p.R286*) and a novel mutation in exon 9 (c.908T >A, p.L303Q) were found in one patient each.

\section{Phenotype (cohort 2)}

The phenotypic details of cohort 2 are described in Table 1. Slight male predominance (57.7\%) was observed in overall cohort. Median age at presentation was 5 years (range: 1-42), with majority of patients presenting in first decade of life (80\%). AI (36.8\%) and achalasia $(36.8 \%)$ were the common presenting features followed by ND (13.7\%) and alacrima (4.2\%). In descending order,

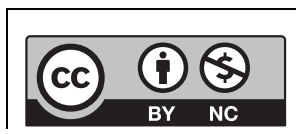

This work is licensed under a Creative Commons Attribution-NonCommercial 4.0 International License. 


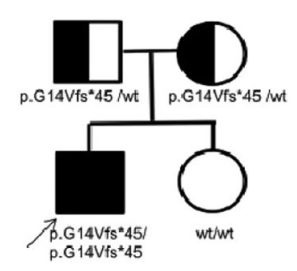

1

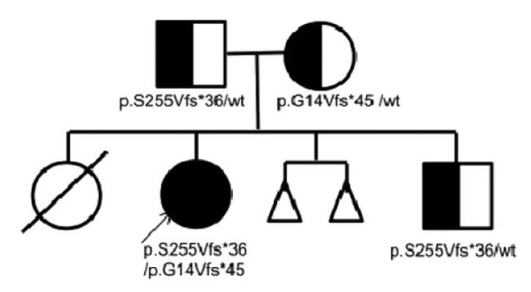

2

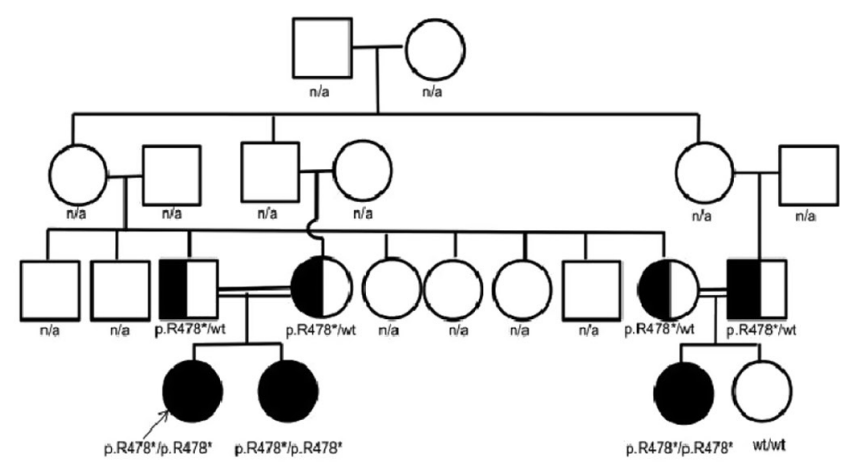

3

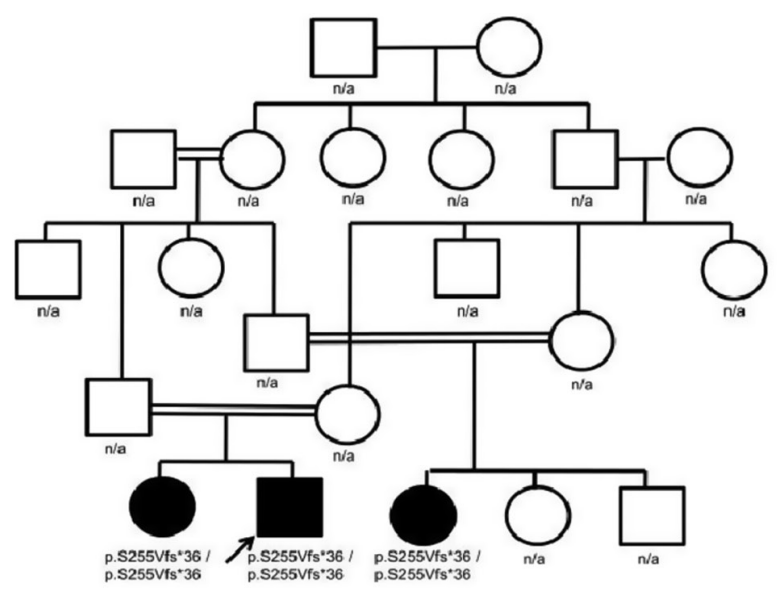

4

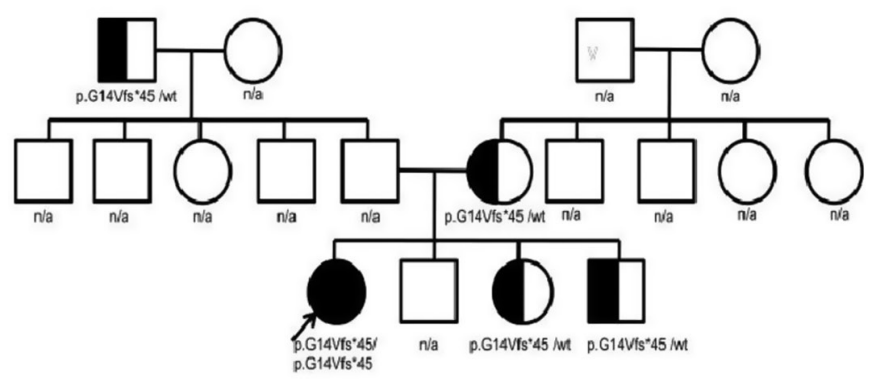

5

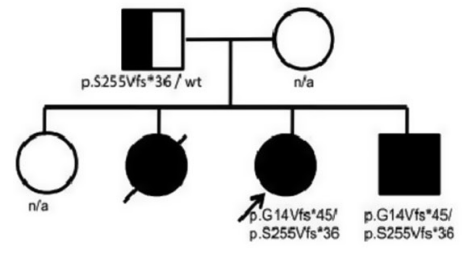

6

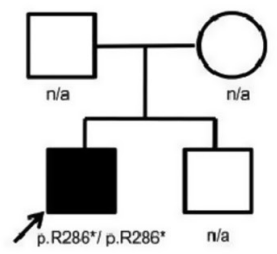

7

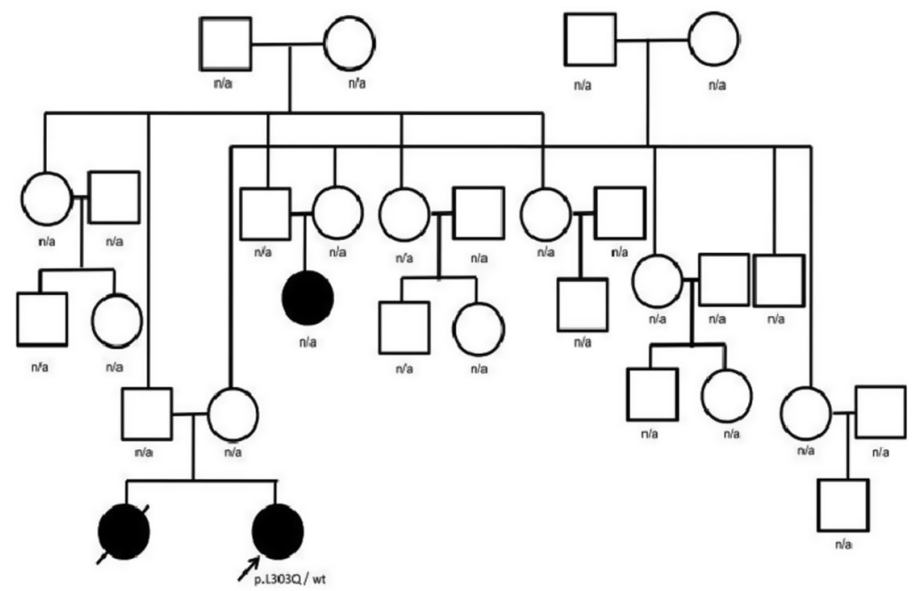

8

Figure 1

Pedigrees of 8 patients with Allgroves syndrome in cohort 1.

the overall prevalence of each feature was: alacrima (99.2\%), achalasia (93.2\%), AI (90.1\%) and ND (79.4\%) (Supplementary Table 2). http://www.endocrineconnections.org
DOI: $10.1530 /$ EC-17-0255
(C) 2017 The authors Published by Bioscientifica Ltd
In the majority of the patients (90.2\%), alacrima was noticed by parents since birth/infancy, while in 4 patients, it was noticed later (range: 2-8 years). The singular

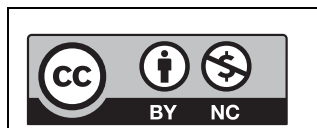

This work is licensed under a Creative Commons Attribution-NonCommercial 4.0 International License. 
Table 1 Description of phenotypic details of cohort 2 ( $n=133$ from 68 publications).

\begin{tabular}{|c|c|c|}
\hline Parameter & Value & $\begin{array}{l}\text { Number of patients where relevant } \\
\text { information reported }\end{array}$ \\
\hline Male:Female & $60 / 44$ & 104 \\
\hline Age at last follow up (years)* & 18.14 (S.D. = 12.9) & 107 \\
\hline Age at presentation (years)** & 5 (range: $1-42$ ) & 90 \\
\hline Percentage of patients presenting at & $72(80 \%)$ & \\
\hline$\leq 10$ years & $11(12.2 \%)$ & \\
\hline $11-20$ years & $4(4.5 \%)$ & \\
\hline $21-30$ years & $2(2.2 \%)$ & \\
\hline $31-40$ years & $1(1.1 \%)$ & \\
\hline \multicolumn{3}{|l|}{$41-50$ years } \\
\hline Presenting feature & $35(36.8 \%)$ & 95 \\
\hline $\mathrm{Al}$ & $35(36.8 \%)$ & \\
\hline Achalasia & $13(13.7 \%)$ & \\
\hline ND & $4(4.2 \%)$ & \\
\hline Alacrima & $4(4.2 \%)$ & \\
\hline Al and achalasia & $2(2.1 \%)$ & \\
\hline Achalasia and ND & $1(1.1 \%)$ & \\
\hline Al and alacrima & $1(1.1 \%)$ & \\
\hline \multicolumn{3}{|l|}{ Al and ND } \\
\hline Prevalence & $132(99.2 \%)$ & 133 \\
\hline Alacrima & $124(93.2 \%)$ & 133 \\
\hline Achalasia & $119(90.1 \%)$ & 132 \\
\hline Al & $100(79.4 \%)$ & 126 \\
\hline \multicolumn{3}{|l|}{ ND } \\
\hline Alacrima & 0 years (range $0-8$ ) & 41 \\
\hline Age at onset** & 8.6 years ( $1-60$ years) & 61 \\
\hline \multicolumn{3}{|l|}{ Age at diagnosis** } \\
\hline $\mathrm{Al}$ & 4 years (range: $0-23$ ) & 41 \\
\hline Age at onset** & 6 years (range: $1-48$ ) & 65 \\
\hline Age at diagnosis** & $5(7.7 \%)$ & 65 \\
\hline Prevalence of subclinical Al & $16(24.6 \%)$ & 65 \\
\hline Prevalence of MC deficiency ${ }^{\#}$ & $3(12.5 \%)$ & 24 (PRA levels available) \\
\hline Non-definite & $3(9 \%)$ & 33 (PAC levels available) \\
\hline \multicolumn{3}{|l|}{ Definite } \\
\hline Achalasia & 8.19 years (S.D. $=7.65$ ) & 47 \\
\hline Age at onset ${ }^{*}$ & 10.55 years $($ S.D. $=8.57)$ & 68 \\
\hline \multicolumn{3}{|l|}{ Age at diagnosis ${ }^{*}$} \\
\hline ND & 12 years (range: $1.1-40)$ & 2744 \\
\hline Age at onset ${ }^{* *}$ & 15.08 years (s.D. = 13.07) & \\
\hline Age at diagnosis* & & \\
\hline
\end{tabular}

*Median value (range) is given as data are skewed in distribution; **mean value (s.D.) is given as data is normally distributed; ${ }^{*}$ mineralocorticoid deficiency was classified as definite when detailed description of biochemical evaluation of plasma renin activity and/or plasma aldosterone levels was ascertained. Otherwise, in patients in whom only presence of MC deficiency was acknowledged irrespective of description of biochemical parameters was classified as non-definite.

Al, adrenal insufficiency; MC deficiency, mineralocorticoid deficiency; ND, neurological dysfunction.

patient reported with the absence of alacrima was documented to have normal Schirmer's test until the age of 18 years (66). AI (median age of onset: 4 years, range: 0-23 years) and achalasia (mean age of onset 8.19 years, S.D. $=7.65$ years) manifested earlier than ND (median age of onset: 12 years, range: $1.1-40$ years). On sub-analysis of patients in whom age at last follow-up was reported, it was observed that majority of patients who had not manifested achalasia (7/7, 100\%) and neurological dysfunction $(18 / 21,85.71 \%)$ at the last follow-up were young ( $\leq 18$ years).
Out of 65 patients with AI, where detailed information was reported, majority (92.3\%) had clinical/symptomatic presentation. Only 7.7\% (5/65) patients had subclinical AI, in whom diagnosis of $\mathrm{AI}$ was established by ACTH stimulation test done as a part of work up, when other components had manifested. Presence or absence of MC deficiency was approved in 65 patients, while PRA and PAC levels were reported in only 24 and 33 patients, respectively. Although MC deficiency was reported to be present in 16 patients $(16 / 65,24.6 \%)$ definite diagnosis of MC deficiency with 
elevated PRA levels $(3 / 24,12.5 \%)$ or low PAC levels $(3 / 33,9 \%)$ could be established in few patients only.

\section{Genotype (cohort 2)}

$34.3 \%$ of patients (37 out of 108 patients in whom details of family history were reported) had history of similar affection in one or more family members, while $45.3 \%$ of patients (53 out of 117 patients in whom relevant information was mentioned) had history of parental consanguinity (Supplementary Table 2).

Overall, 65 different mutations were reported in 127 patients, $65.4 \%(n=83)$ in homozygous state, 33\% $(n=42)$ in compound heterozygous state and $1.6 \%(n=2)$ in heterozygous state. Mutations were not identified in $A A A S$ gene in 6 patients $(4.7 \%)$. Common mutations included frameshift $(n=19)$, nonsense $(n=19)$, missense $(n=15)$, and splice-site $(n=8)$ mutations. Additionally, an indel mutation and mutations in the intronic region, regulatory element and 5' UTR were found in one patient each. Figure 2 collates the various mutations found in $A A A S$ gene (from cohorts 1 and 2). Fourteen mutations were recurrent (defined as occurring in $\geq 3$ unrelated individuals). Some of the recurring mutations exhibit clustering to particular geographical regions (Fig. 3). These include c.1331+1G $>$ A (North Africa and USA), c.1432C > T; p.R478* (Europe), c.787T >C; p.S263P (Europe), c.771delG; p.R258Gfs*33 (China), c.43C>A; p.G14Vfs*45 (Europe and India, from cohort 1) and c.762delC; p.S255Vfs*36 (India, from cohort 1).

\section{Phenotype-genotype correlation analysis}

To study phenotype-genotype correlation, patients (from both cohorts 1 and 2) were divided into two groups: Group T-patients with mutations resulting in truncating protein, and group NT-patients with mutations resulting in non-truncating protein. Patients with nonsense mutations, frameshift mutations and deletions were grouped as truncating, while those with missense mutations were grouped as non-truncating ones. Patients having compound heterozygous state with one truncating and other non-truncating mutation were classified in group NT, as it has been observed that patients having at least one missense (non-truncating) mutation have a milder phenotype than those having both truncating ones (21). Three out of 8 splice-site mutations (c.1331+1; $\mathrm{G}>\mathrm{A}$, c.546-2A $>\mathrm{C}$ and c. $400-2 \mathrm{~A}>\mathrm{G}$ ) were previously reported to result in truncating proteins and hence were classified in group T. Remaining 5 splice-site mutations could not be sub-classified due to the absence of in vitro mRNA studies. These 5 patients with splice-site mutations, three patients who had heterozygous mutations, and six mutation negative patients, were excluded from analysis of genotype-phenotype correlation. The result of genotype-phenotype analysis for remaining 127 patients is shown in Table 2. As compared to NT group, patients in $\mathrm{T}$ group had significantly higher prevalence and higher chances of presentation with AI. Moreover, median age of diagnosis of $\mathrm{AI}$ in $\mathrm{T}$ group was significantly lower than that of NT group. Subclinical AI was found in NT group only. As compared to T group, patients within NT group had significantly higher overall prevalence and higher chances of presentation with ND. However, median age at onset of ND in T group was significantly lower than that of NT group.

\section{Discussion}

Triple A syndrome (TAS), though a rare disorder, is an important genetic cause of primary AI in children. Current study includes the first description of Indian series of AS patients (cohort 1). Additionally, it includes systematic

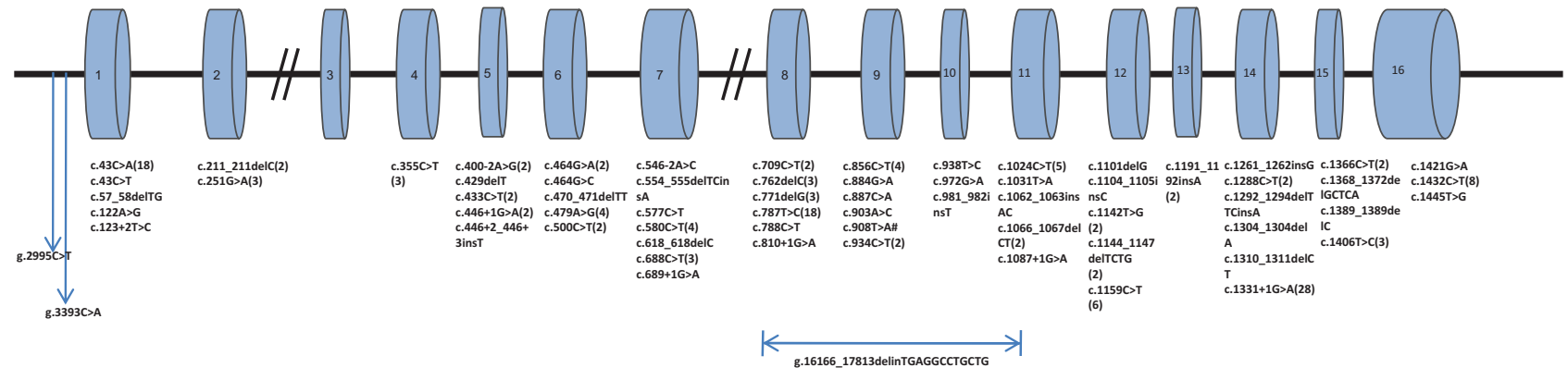

Figure 2

Schematic diagram of AAAS gene distribution of 66 mutations reported to date (1 from cohort 1 and 65 from cohort 2).

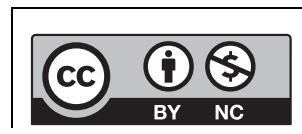

This work is licensed under a Creative Commons Attribution-NonCommercial 4.0 International License. 


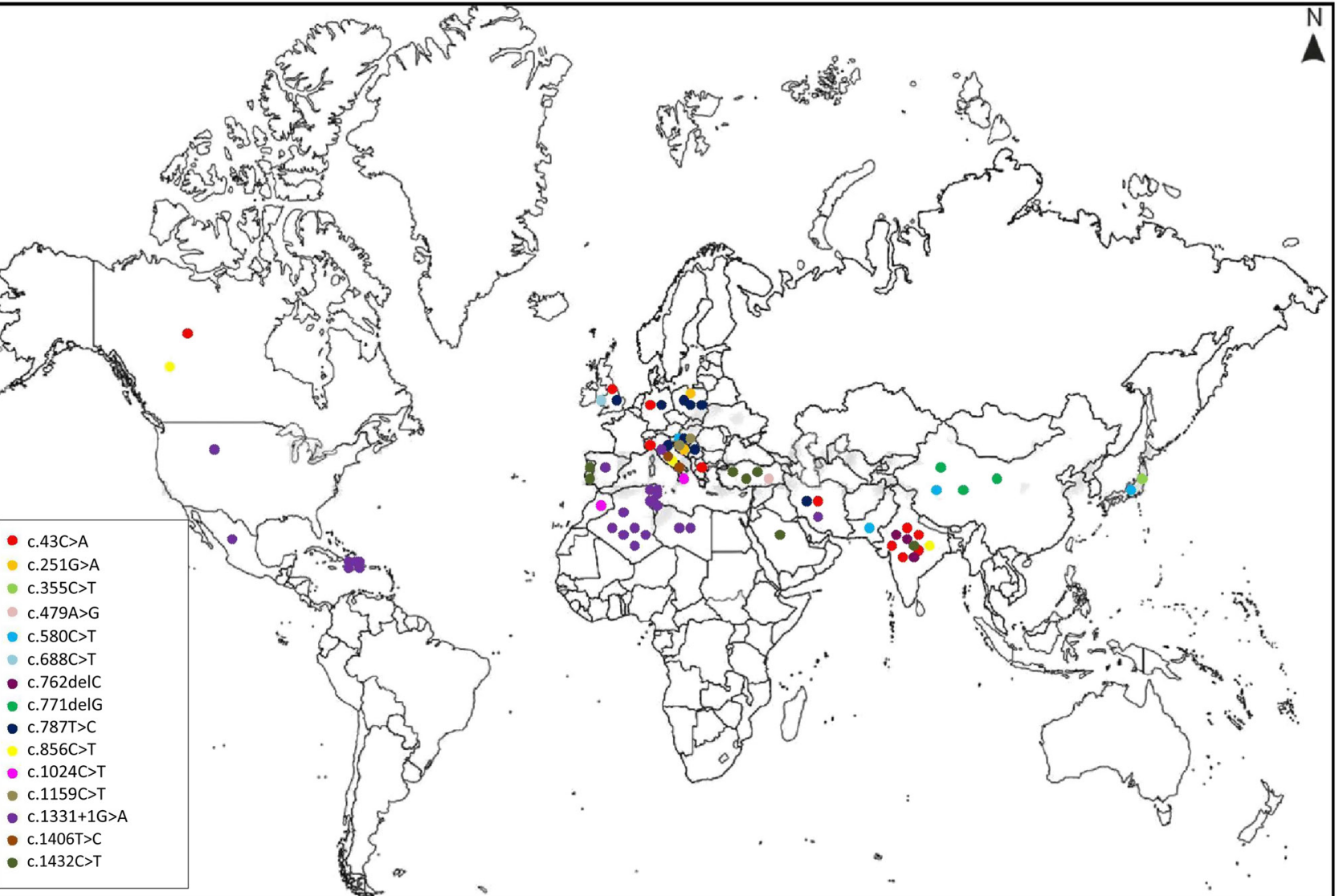

Figure 3

Geographical distribution of 15 recurrent mutations in AAAS gene.

review of phenotype-genotype spectrum of genotyped cases of TAS reported to date (cohort 2).

Although small sample size of our cohort limits statistical comparison with cohort 2, we found that the phenotypic spectrum of our patients was largely similar to that of other ethnicities (cohort 2) except for a lower prevalence of ND in our patients (4/8 patients in cohort 1 vs $80 \%$ in cohort 2). Apart from a possible referral bias to an endocrine center, we believe this disparity can be attributed to younger age of our patients. All patients in our cohort without ND are young (5.5-13 years at last follow-up). This conforms with the observation that $87.5 \%$ of patients in cohort 2 who have not yet manifested ND were younger than 18 years.

In cohort 2, majority of TAS patients presented in first two decades of life, with either achalasia or AI. Hence TAS, though an uncommon etiology for pediatric achalasia (7-15\%) or pediatric AI (1\%) per se, should be considered in the etiological workup of these disorders in children $(73,74)$. Seven patients $(8 \%)$ in cohort 2 presented in 3rd to 5 th decades of life, suggesting that diagnosis of TAS

http://www.endocrineconnections.org DOI: 10.1530/EC-17-0255

2017 The authors Published by Bioscientifica Ltd should be considered in adults as well. Interestingly, these seven patients presented either with ND or achalasia, and none of them presented with AI. The reason for this differential mode of disease presentation in adults remains unknown and needs further study.

Analysis of cohort 2 reveals that a patient with TAS can present with any one of the four cardinal features and that the symptoms evolve over a period of time, suggesting TAS to be a progressive disorder. Therefore, it is prudent to exercise high index of suspicion for diagnosis, even in patients presenting with isolated components of TAS. Alacrima, rarely a presenting feature, is the earliest to appear and is present in almost every (99\%) patient. Hence, in a patient presenting with AI, achalasia or ND, presence of alacrima can point towards the diagnosis of TAS, while its absence almost rules out this rare condition. Achalasia, present in $93 \%$ of patients, was second most prevalent disorder. Its prevalence was higher than what is classically reported in earlier reviews (75\%) (1).

AI in TAS is commonly isolated glucocorticoid deficiency. In their original report, Allgrove and coworkers

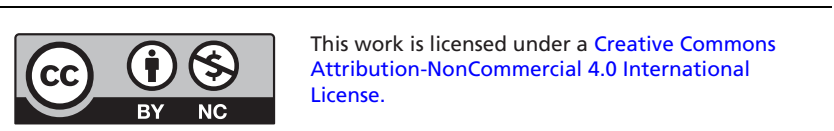




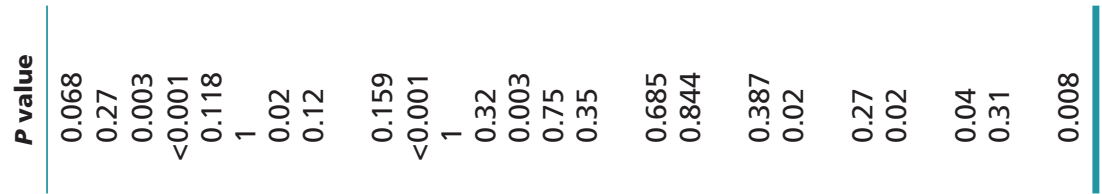
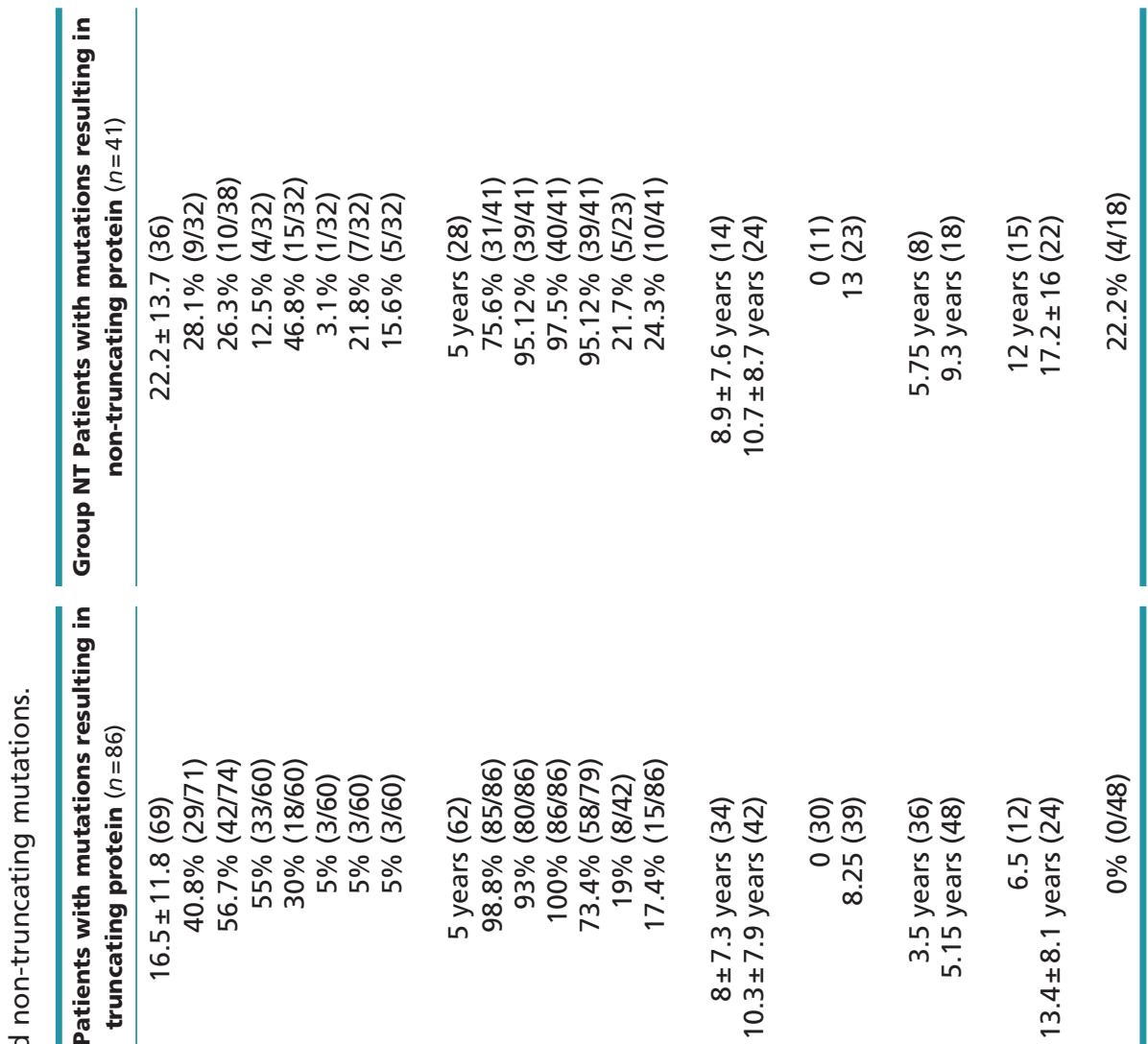

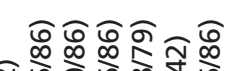

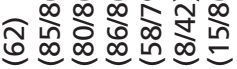
๘ั

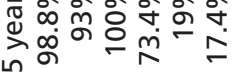

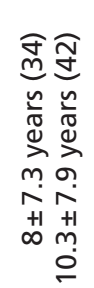

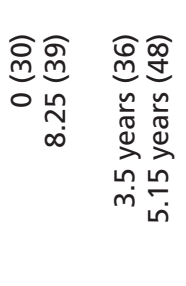
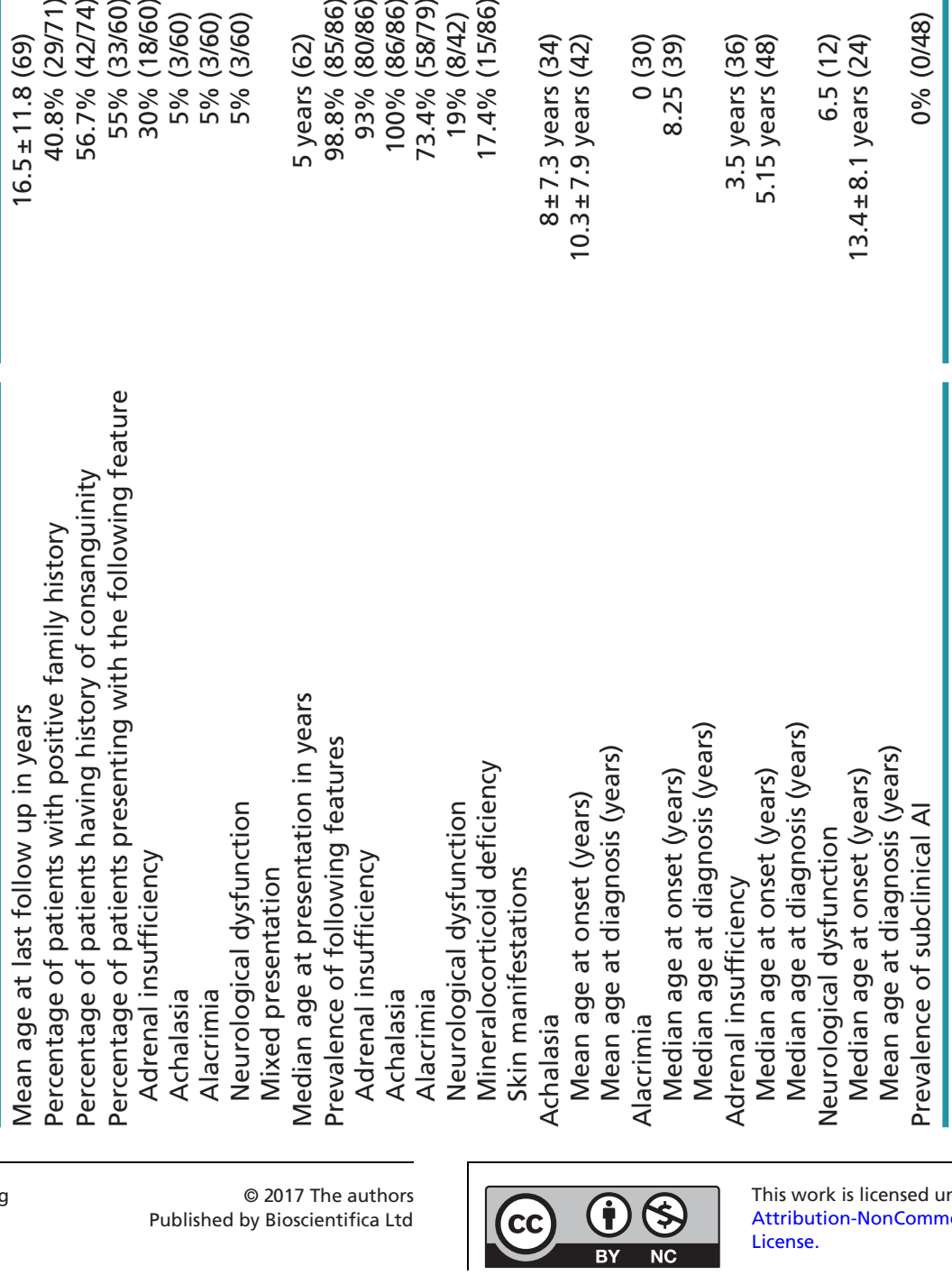

This work is licensed under a Creative Commons Attribution-NonCommercial 4.0 International License. 
described it as a variant of familial glucocorticoid deficiency with histopathological evidence of a preserved zona glomerulosa (3). Later, MC deficiency was also reported in TAS $(51,71,72)$. Grant and coworkers reported 3 patients to be MC deficient (all 3 with typical electrolyte abnormalities and two with additional elevated PRA) in a cohort of 20 TAS patients, suggesting 15\% prevalence of MC deficiency in TAS (75). In close analysis of cohort 2 , we found that definite MC deficiency was uncommon (12.5\% (3/24) in those with PRA levels reported; 9\% (3/33) in those with PAC levels reported). Similarly, none of the patients in cohort 1 had MC deficiency as documented with normal PRA levels. These findings emphasize the need of establishing definite diagnosis of MC deficiency with study of PAC and PRA levels, before starting fludrocortisone replacement. The pathophysiology of MC axis involvement remains unknown and may be proposed to be due to progressive degeneration of zona glomerulosa and/or autonomic dysfunction.

Half of patients in cohort 1 and one-third (34.3\%) of patients in cohort 2 were familial cases. Additionally, there was higher prevalence of parental consanguinity (45\%) in patients of cohort 2, which emphasizes autosomal recessive mode of inheritance for TAS. The current study revealed 67 different mutations in $A A A S$ gene, including a novel mutation from cohort 1 . The majority $(7 / 8$ patients in cohort 1 and 94\% in cohort 2) had mutations in homozygous or compound heterozygous state consistent with AR inheritance. Two patients in cohort 2 were heterozygous for mutations $(58,72)$ (c.856C $>$ T (p.R286*) and c.1331+1; G>A (IVS14+1 G>A)), which have been previously reported in homozygous as well as compound heterozygous states $(4,38,44,72)$. Interestingly, in these previous reports, familial segregation analysis documented no clinical phenotype of disease in healthy parents or unaffected siblings, who were heterozygous (carriers) for these mutations. The plausible explanation for this phenomenon could be the presence of another mutation in noncoding sequences of second allele of $A A A S$ gene, which remained unidentified with current detection methods or another unknown gene mutation, which affects the expression and/or function of AAAS gene.

Six patients from cohort 2 tested negative for mutations in AAAS gene $(47,49,58,68)$. This can be postulated to be due to unidentified large deletions (missed on Sanger sequencing) or mutations in uncharted intronic or regulatory regions. In few mutation-negative TAS families, even linkage to markers of the AAAS gene region on $12 q 13$ was found to be negative (76). Hence, the possibility of mutations in genes other than $A A A S$ gene with phenotype similar to TAS cannot be ruled out, further signifying the genetic heterogeneity of TAS.

Mutations were found throughout the AAAS gene, suggesting no hotspots. However, based on the observation of geographic clustering of apparently unrelated patients with same mutations, several authors have suggested regional founder effects for certain recurring mutations, which were substantiated by haplotype analysis (4, 5, $33,41,44)$. Based on haplotype analysis, Genin and coworkers predicted that c. $1331+1 \mathrm{G}>\mathrm{A}$ mutation originated in North African population 1000-1175 years ago (77). In our analysis, we identified 15 recurrent mutations, with few exhibiting regional clustering. These represent higher background (region specific) carrier rate, suggesting a common ancestral origin. Thus, ethnic origin of a patient may help in targeted molecular diagnosis of TAS. Facilitation of genetic diagnosis by this approach has been attempted by Kallabi and coworkers who performed targeted sequencing precisely for the region of $A A A S$ gene (172-bp fragment that covers the junction between exon 14 and intron 14) corresponding to commonly described North African ancestral mutation (c. $1331+1 \mathrm{G}>\mathrm{A})$ in two Libyan AS families and confirmed the presence of same mutation (13). Kallabi and coworkers further proposed that doing restricted enzymatic digestion by Mva I of the targeted PCR product can facilitate family screening of affected individuals (13).

Even before genetic etiology of TAS could be elucidated, intra-familial variability in clinical phenotype was well recognized $(1,78)$. Thereafter, study of genotypephenotype correlation in TAS patients was based on observing variability in clinical manifestations in patients having same individual mutation $(20,41,54)$. This approach revealed the absence of a consistent genotypephenotype correlation, which was proposed to be due to effect of other modifying genes or environmental factors on the phenotype of TAS.

Few authors have observed that the patients with missense mutations had different phenotypes than those with truncating mutations (21). We used similar approach to study the genotype-phenotype correlation in our study and observed significant clinical differences between the two groups. Patients in T group were more likely to present with symptomatic AI, diagnosed to have $\mathrm{AI}$ at younger age and have overall higher prevalence of AI as compared to NT group. Prevalence/presentation of alacrima and achalasia did not differ among these groups. Patients in NT group were more likely to present with ND, with onset of ND at later age and have higher prevalence

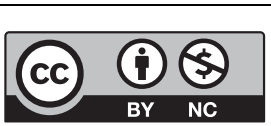


of ND as compared to $\mathrm{T}$ group. With the underlying causative mechanisms unknown, our observation of differing clinical profiles of the two groups calls for future research. In vitro studies have shown that mutations truncating $\mathrm{N}$ or $\mathrm{C}$ terminals, and most non-truncating mutations, especially those in WD repeat region result in mis-localisation of ALADIN protein, potentially causing functional disruption of interaction of mutant ALADIN with other associated proteins (79). A possible interaction of ALADIN with PGRMC2, a regulator of the cell cycle, and participation of ALADIN in cell division by spatial regulation of Aurora A was described recently $(80,81)$. It can be speculated that during process of cell division, missense mutations (non-truncating) with the presence of a functionally impaired protein may have different consequences compared to that of a truncated protein, which in most cases, undergoes degradation by the ubiquitin-proteasome pathway, accounting for phenotypic differences in clinical features.

Most previous reports on TAS have limitation of small sample size. Besides being the first description of largest Indian series of genetically proven TAS patients, the strength of our study includes collation of individual data of genotyped TAS patients worldwide. We believe that our study adds to the comprehensive understanding of phenotypic and genotypic spectrum of this rare disorder. However, the study has important limitation of non-uniformity of data, as complete phenotypic information was not available for each reported patient. Also, phenotypic information of pre-2000 era (before $A A A S$ gene was described) is not included in the current study, which may make the phenotypic prevalence data of cohort 2 not completely representative. Progressive nature of the syndrome forms an additional limitation for genotype-phenotype correlation (62).

\section{Conclusion}

Clinical profile of Indian TAS patients is largely similar to that of patients of other ethnicities. Although TAS is predominantly a disorder of children and adolescents, it can manifest in adulthood up to 5 th decade of life. Alacrima is the earliest and most consistent finding of TAS. MC deficiency is less common while achalasia is more common than it was previously assumed. Some recurrent mutations show regional clustering and may suggest common ancestral mutation/founder effect. Two mutations (p.G14Vfs*45 and p.S255Vfs*36) account for majority of the $A A A S$ mutations in our patients.
Phenotypic profile of patients with truncating mutations differs systematically from that of patients with nontruncating mutations. Future research is warranted to put this observation in perspective.

\section{Supplementary data}

This is linked to the online version of the paper at http://dx.doi.org/10.1530/ EC-17-0255.

\section{Declaration of interest}

The authors declare that there is no conflict of interest that could be perceived as prejudicing the impartiality of the research reported.

\section{Funding}

This work was supported by a DFG grant HU 895/5-1 and HU 895/5-2 (Clinical Research Unit 252) to A H.

\section{References}

1 Clark AJ \& Weber A. Adrenocorticotropin insensitivity syndromes. Endocrine Reviews 199819 828-843. (doi:10.1210/edrv.19.6.0351)

2 Sarathi V \& Shah NS. Triple A syndrome. Advances in Experimental Medicine and Biology 2010685 1-8. (doi:10.1007/978-1-44196448-9_1)

3 Allgrove J, Clayden GS, Grant DB \& Macaulay JC. Familial glucocorticoid deficiency with achalasia of the cardia and deficient tear production. Lancet 19781 1284-1286. (doi:10.1016/S01406736(78)91268-0)

4 Handschug K, Sperling S, Yoon S-JK, Hennig S, Clark AJ \& Huebner A. Triple A syndrome is caused by mutations in AAAS, a new WD-repeat protein gene. Human Molecular Genetics 200110 283-290. (doi:10.1093/hmg/10.3.283)

5 Tullio-Pelet A, Salomon R, Hadj-Rabia S, Mugnier C, de Laet MH, Chaouachi B, Bakiri F, Brottier P, Cattolico L, Penet C, et al. Mutant WD-repeat protein in triple-A syndrome. Nature Genetics 200026 332-335. (doi:10.1038/81642)

6 Hirano M, Furiya Y, Asai H, Yasui A \& Ueno S. ALADINI482S causes selective failure of nuclear protein import and hypersensitivity to oxidative stress in triple A syndrome. PNAS 2006103 2298-2303. (doi:10.1073/pnas.0505598103)

7 Bornstein SR, Allolio B, Arlt W, Barthel A, Don-Wauchope A, Hammer GD, Husebye ES, Merke DP, Murad MH, Stratakis CA, et al. Diagnosis and treatment of primary adrenal insufficiency: an Endocrine Society Clinical Practice Guideline. Journal of Clinical Endocrinology and Metabolism 2016101 364-389. (doi:10.1210/ jc.2015-1710)

8 Bustanji H, Sahar B, Huebner A, Ajlouni K, Landgraf D, Hamamy H \& Koehler K. Triple A syndrome with a novel indel mutation in the AAAS gene and delayed puberty. Journal of Pediatric Endocrinology and Metabolism 201528 933-936. (doi:10.1515/jpem-2014-0401)

9 Hansen ML, Frederiksen AL \& Juhl CB. Novel mutation in the AAAS gene in a severely affected triple-A syndrome patient. Endocrinology and Metabolic Syndrome 20154 3. (doi:10.4172/2161-1017.1000186)

10 Sanghvi J, Asati AA, Kumar R \& Huebner A. Novel mutations in a patient with triple A syndrome. Indian Pediatrics 201552 805-806. (doi:10.1007/s13312-015-0722-y)

11 Li W, Gong C, Qi Z, Wu DI \& Cao B. Identification of AAAS gene mutation in triple A syndrome: a report of three cases. Experimental and Therapeutic Medicine 201510 1277-1282. (doi:10.3892/ etm.2015.2677)

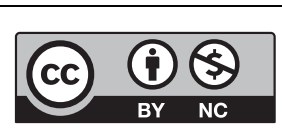

This work is licensed under a Creative Commons Attribution-NonCommercial 4.0 International License. 
12 Zimmer V, Vanderwinden JM, Zimmer A, Ostertag D, Strittmatter M, Koehler K, Huebner A \& Lammert F. Organspecific neurodegeneration in triple A syndrome-related achalasia. American Journal of Medicine 2015128 e9-e12. (doi:10.1016/j. amjmed.2015.04.025)

13 Kallabi F, Ben Rebeh I, Felhi R, Sellami D, Masmoudi S, Keskes L \& Kamoun H. Molecular analysis of Libyan families with triple A syndrome: geographic expansion of the ancestral mutation c. 1331+1G>A in North Africa. Hormone Research in Paediatrics 2016 85 18-21. (doi:10.1159/000441653)

14 Aragona P, Rania L, Roszkowska AM, Puzzolo D, Micali A, Pisani A, Salzano G \& Messina MF. 4A syndrome: ocular surface investigation in an Italian young patient. BMC Ophthalmology 201414155 (doi:10.1186/1471-2415-14-155)

15 Cherif Ben Abdallah L, Lakhoua Y, Nagara M, Khiari K, Elouej S, Messaoud O, Bouyacoub Y, Romdhane L, Turki Z, Abdelhak S, et al. A Tunisian patient with two rare syndromes: triple A syndrome and congenital hypogonadotropic hypogonadism. Hormone Research in Paediatrics 201482 338-343. (doi:10.1159/000365888)

16 Bizzarri C, Benevento D, Terzi C, Huebner A \& Cappa M. Triple A (Allgrove) syndrome: an unusual association with syringomyelia. Italian Journal of Pediatrics 201339 39. (doi:10.1186/1824-728839-39)

17 Yang H, Zhang H, Lu L, Wang O, Xing X, Zhang M \& Lu Z. Clinical and genetic characterization of a Chinese patient with triple $\mathrm{A}$ syndrome and novel compound heterozygous mutations in the AAAS gene. Journal of Pediatric Endocrinology and Metabolism 201326 389-391. (doi:10.1515/jpem-2012-0284)

18 Mazzone L, Postorino V, Peppo L D, Vassena L, Fatta L, Armando M, Scirè G, Cappa $M$ \& Vicari S. Longitudinal neuropsychological profile in a patient with triple A syndrome. Case Reports in Pediatrics 2013 2013 604921. (doi:10.1155/2013/604921)

19 Ikemoto S, Sakurai K, Kuwashima N, Saito Y, Miyata I, Katsumata N \& Ida H. A case of triple A syndrome with a novel IVS7+1 G>A mutation of the AAAS gene. Clinical Pediatric Endocrinology 201221 11-13. (doi:10.1297/cpe.21.11)

20 Dumic M, Barišic N, Kusec V, Stingl K, Skegro M, Stanimirovic A, Koehler K \& Huebner A. Long-term clinical follow-up and molecular genetic findings in eight patients with triple A syndrome. European Journal of Pediatrics 2012171 1453-1459. (doi:10.1007/s00431-0121745-1)

21 Ikeda M, Hirano M, Shinoda K, Katsumata N, Furutama D Nakamura K, Ikeda S, Tanaka T, Hanafusa T, Kitajima H, et al. Triple A syndrome in Japan. Muscle and Nerve 201348 383-386. (doi:10.1002/ mus.23770)

22 Marín S, Casano-Sancho P, Villarreal-Peña N, Sebastiani G, Pinillos S, Pérez-Dueñas B, Hwa V, Rosenfeld RG \& Ibáñez L. Triple A syndrome in a patient with genetic growth hormone insensitivity: phenotypic effects of two genetic disorders. Hormone Research in Paediatrics 2012 77 63-68. (doi:10.1159/000335235)

23 Papageorgiou L, Mimidis K, Katsani KR \& Fakis G. The genetic basis of triple A (Allgrove) syndrome in a Greek family. Gene $2013 \mathbf{5 1 2}$ 505-509. (doi:10.1016/j.gene.2012.10.008)

24 Yassaee VR, Soltani Z \& Ardakani BM. Mutation spectra of the AAAS gene in Iranian families with triple A syndrome. Archives of Medical Research 201142 163-168. (doi:10.1016/j.arcmed.2011.02.006)

25 Dumić M, Barišić N, Rojnić-Putarek N, Kušec V, Stanimirović A, Koehler K \& Huebner A. Two siblings with triple A syndrome and novel mutation presenting as hereditary polyneuropathy. European Journal of Pediatrics 2011170 393-396. (doi:10.1007/s00431-010-1314-4)

26 Wallace I R \& Hunter S J. AAA syndrome-adrenal insufficiency, alacrima and achalasia. Quarterly Journal of Medicine 2012105 803-804. (doi:10.1093/qjmed/hcr145)

27 Dixit A, Chow G \& Sarkar A. Neurologic presentation of triple A syndrome. Pediatric Neurology 201145 347-349 (doi:10.1016/j. pediatrneurol.2011.07.003)
28 Moschos MM, Margetis I, Koehler K, Gatzioufas Z \& Huebner A. New ophthalmic features in a family with triple A syndrome. International Ophthalmology 201131 239-243. (doi:10.1007/s10792-011-9450-z)

29 Kunte H, Nümann A, Ventz M, Siebert E \& Harms L. Wernicke's encephalopathy in a patient with triple A (Allgrove) syndrome. Journal of Neurology 2011258 1882-1884. (doi:10.1007/s00415-0116012-2)

30 Alhussaini B, Gottrand F, Goutet JM, Scaillon M, Michaud L, Spyckerelle C, Viola S \& Lamblin MD. Clinical and manometric characteristics of triple A syndrome. Journal of Pediatric Gastroenterology and Nutrition 201153 271-274. (doi:10.1097/ MPG.0b013e31821456ba)

31 Milenkovic T, Zdravkovic D, Savic N, Todorovic S, Mitrovic K, Koehler K \& Huebner A. Triple A syndrome: 32 years experience of a single centre (1977-2008). European Journal of Pediatrics 2010169 1323-1328. (doi:10.1007/s00431-010-1222-7)

32 Nakamura K, Yoshida K, Yoshinaga T, Kodaira M, Shimojima Y, Takei Y, Morita H, Kayanuma K \& Ikeda S. Adult or late-onset triple A syndrome: case report and literature review. Journal of Neurological Sciences 2010297 85-88. (doi:10.1016/j.jns.2010.07.006)

33 Krull I, M-Woelfle M, Bärlocher K, Koehler K, Huebner A \& Brändle $\mathrm{M}$. Two patients with an identical novel mutation in the AAAS gene and similar phenotype of triple A (Allgrove) syndrome. Experimental and Clinical Endocrinology and Diabetes 2010118 530-536. (doi:10.1055/s-0030-1247516)

34 Palka C, Giuliani R, Brancati F, Mohn A, Di Muzio A, Calabrese O, Huebner A, De Grandis D, Chiarelli F, Ferlini A, et al. Two Italian patients with novel AAAS gene mutation expand allelic and phenotypic spectrum of triple A (Allgrove) syndrome. Clinical Genetics 201077 298-301. (doi:10.1111/j.1399-0004.2009.01348.x)

35 Luigetti M, Pizzuti A, Bartoletti S, Houlden H, Pirro C, Bottillo I, Madia F, Conte A, Tonali PA \& Sabatelli M. Triple A syndrome: a novel compound heterozygous mutation in the AAAS gene in an Italian patient without adrenal insufficiency. Journal of Neurological Sciences 2010290 150-152. (doi:10.1016/j.jns.2009.12.005)

36 Villanueva-Mendoza C, artínez-Guzmán O, Rivera-Parra D $\&$ Zenteno JC. Triple A or Allgrove syndrome. A case report with ophthalmic abnormalities and a novel mutation in the AAAS gene. Ophthalmic Genetics 200930 45-49. (doi:10.1080/13816810802502962)

37 Huynh T, McGown I, Nyunt O, Cowley D, Harris M, Cotterill AM \& Leong GM. A novel V185DfsX4 mutation of the AAAS gene in a 2-year-old boy with triple A syndrome. Clinical Pediatric Endocrinology 200918 73-75. (doi:10.1297/cpe.18.73)

38 Messina MF, Autunno M, Koehler K, Russo M, Arrigo T, Crisafulli G, Huebner A \& De Luca F. Upper and lower motor neuron involvement as presenting manifestation of triple A syndrome. Journal of Endocrinological Investigations 200932 482-483. (doi:10.1007/ BF03346490)

39 Thümmler S, Huebner A \& Baechler-Sadoul E. Triple A syndrome: two novel mutations in the AAAS gene. BMJ Case Reports 20092009 pii: bcr09.2008.0984. (doi:10.1136/bcr.09.2008.0984)

40 Toromanovic A, Tahirovic H, Milenkovic T, Koehler K, Kind B, Zdravkovic D, Hasanhodzic M \& Huebner A. Clinical and molecular genetic findings in a 6-year-old Bosnian boy with triple A syndrome. European Journal of Pediatrics 2009168 317-320. (doi:10.1007/ s00431-008-0758-2)

41 Milenkovic T, Koehler K, Krumbholz M, Zivanovic S, Zdravkovic D $\&$ Huebner A. Three siblings with triple A syndrome with a novel frameshift mutation in the AAAS gene and a review of 17 independent patients with the frequent p. Ser263Pro mutation. European Journal of Pediatrics 2008167 1049-1055. (doi:10.1007/ s00431-007-0640-7)

42 Koehler K, Brockmann K, Krumbholz M, Kind B, Bönnemann C, Gärtner J \& Huebner A. Axonal neuropathy with unusual pattern of amyotrophy and alacrima associated with a novel AAAS mutation

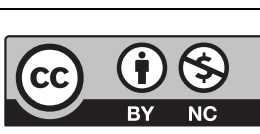


p.Leu430Phe. European Journal of Human Genetics 200816 1499-1506. (doi:10.1038/ejhg.2008.132)

43 Strauss M, Koehler K, Krumbholz M, Huebner A, Zierz S \& Deschauer M. Triple A syndrome mimicking ALS. Amyotrophic Lateral Sclerosis 20089 315-317. (doi:10.1080/17482960802259016)

44 Chang AJ, Kline MM, Currie Y, Perez MO, Hartiala J, Wijesuriya H, Buchanan TA, Watanabe RM \& Allayee H. Triple A syndrome in a Mexican American family is caused by an ancestral mutation derived from North Africa. Clinical Genetics 200873 385-387. (doi:10.1111/ j.1399-0004.2008.00965.x)

45 Buderus S, Utsch B, Huebner A, Lentze MJ \& Roth C. Dysphagia due to triple A syndrome: successful treatment of achalasia by balloon dilatation. Experimental and Clinical Endocrinology and Diabetes 2007 115 533-536. (doi:10.1055/s-2007-973852)

46 Salmaggi A, Zirilli L, Pantaleoni C, De Joanna G, Del Sorbo F, Koehler K, Krumbholz M, Huebner A \& Rochira V. Late-onset triple A syndrome: a risk of overlooked or delayed diagnosis and management. Hormone Research in Pediatrics 200870 364-372. (doi:10.1159/000161867)

47 Onat AM, Pehlivan Y, Buyukhatipoglu H, Igci YZ, Okumus S, Arikan C \& Oguzkan S. Unusual presentation of triple A syndrome mimicking Sjögren's syndrome. Clinical Rheumatology 200726 1749-1751. (doi:10.1007/s10067-006-0498-5)

48 Qin K, Du X \& Rich BH. An Alu-mediated rearrangement causing a $3.2 \mathrm{~kb}$ deletion and a novel two base pair deletion in AAAS gene as the cause of triple A syndrome. Molecular Genetics and Metabolism 200792 359-363. (doi:10.1016/j.ymgme.2007.08.116)

49 Gilio F, Di Rezze S, Conte A, Frasca V, Iacovelli E, Marini Bettolo C, Gabriele M, Giacomelli E, Pizzuti A, Pirro C, et al. Case report of adult-onset triple A syndrome. Neurological Sciences 200728 331-335. (doi:10.1007/s10072-007-0848-3)

50 Mukhopadhya A, Danda S, Huebner A \& Chacko A. Mutations of the AAAS gene in an Indian family with Allgrove's syndrome. World Journal of Gastroenterology 200612 4764-4766. (doi:10.3748/wjg.v12. i29.4764)

51 Ismail EA, Tulliot-Pelet A, Mohsen AM \& Al-Saleh Q. Triple A syndrome with features of familial dysautonomia: a novel mutation in the AAAS gene. Acta Paediatrica 200695 1140-1143. (doi:10.1080/08035250500538999)

52 Dusek T, Korsic M, Koehler K, Perkovic Z, Huebner A \& Korsic M. A novel AAAS gene mutation (p.R194X) in a patient with triple A syndrome. Hormone Research in Paediatrics 200665 171-176. (doi:10.1159/000092003)

53 Lam YY, Lo IF, Shek CC, Tong TM, Ng DK, Tong TF, Choi MS, Lam ST $\&$ Ho CS. Triple A syndrome-the first Chinese patient with novel mutations in the AAAS gene. Journal of Pediatric Endocrinology and Metabolism 200619 765-770. (doi:10.1515/JPEM.2006.19.5.765)

54 Lovrecic L, Pelet A \& Peterlin B. Heterogeneity of the triple A syndrome and assessment of a case. Genetic Counseling $2006 \mathbf{1 7}$ 191-195.

55 Borhani Haghighi A, Houlden H, Lankarani KB, Taghavi A, Masnadi K, Ashraf AR \& Safari A. A novel DNA sequence variation in the first genetically confirmed triple A syndrome in Iran. Journal of Clinical Neuromuscular Disease 20067 123-127. (doi:10.1097/01. cnd.0000208261.93426.ab)

56 Salehi M, Houlden H, Sheikh A \& Poretsky L. The diagnosis of adrenal insufficiency in a patient with triple A syndrome and a novel mutation in the ALADIN gene. Metabolism 200554 200-205. (doi:10.1016/j.metabol.2004.08.013)

57 Iwanczak F, Smigiel R, Blitek A \& Huebner A. The triple A syndrome confirmed by molecular analysis: a case report of 7-year-old boy. Journal of Pediatric Gastroenterology and Nutrition 200540 87-89.

58 Brooks BP, Kleta R, Stuart C, Tuchman M, Jeong A, Stergiopoulos SG, Bei T, Bjornson B, Russell L, Chanoine JP, et al. Genotypic heterogeneity and clinical phenotype in triple A syndrome: a review of the NIH experience 2000-2005. Clinical Genetics 200568 215-221. (doi:10.1111/j.1399-0004.2005.00482.x)

59 Roman S, Nicolino M, Mion F, Tullio-Pelet A, Péré-Vergé D \& Souquet JC. Triple A syndrome: a rare etiology of adult achalasia. Digestive Diseases and Sciences 200550 440-442. (doi:10.1007/s10620005-2454-7)

60 Brooks BP, Kleta R, Caruso RC, Stuart C, Ludlow J \& Stratakis CA. Triple-A syndrome with prominent ophthalmic features and a novel mutation in the AAAS gene: a case report. BMC Ophthalmology 20044 7. (doi:10.1186/1471-2415-4-7)

61 Kinjo S, Takemoto M, Miyako K, Kohno H, Tanaka T \& Katsumata N. Two cases of triple A syndrome with mutations in the AAAS gene. Endocrine Journal 200451 473-477. (doi:10.1507/endocrj.51.473)

62 Yuksel B, Braun R, Topaloglu AK, Mungan NO, Ozer G \& Huebner A. Three children with triple A syndrome due to a mutation (R478X) in the AAAS gene. Hormone Research in Paediatrics 200461 3-6. (doi:10.1159/000075190)

63 Roubergue A, Apartis E, Vidailhet M, Mignot C, Tullio-Pelet A, Lyonnet $S$ \& de Villemeur TB. Myoclonus and generalized digestive dysmotility in triple A syndrome with AAAS gene mutation. Movement Disorders 200419 344-346. (doi:10.1002/mds.10660)

64 Barat P, Goizet C, Tullio-Pelet A, Puel O, Labessan C \& Barthelemy A. Phenotypic heterogeneity in AAAS gene mutation. Acta Paediatrica 200493 1257-1259. (doi:10.1111/j.1651-2227.2004.tb02760.x)

65 Reshmi-Skarja S, Huebner A, Handschug K, Finegold DN, Clark AJ \& Gollin SM. Chromosomal fragility in patients with triple A syndrome. American Journal of Medical Genetics 2003 117A 30-36. (doi:10.1002/ajmg.a.10846)

66 Prpic I, Huebner A, Persic M, Handschug K \& Pavletic M. Triple A syndrome: genotype-phenotype assessment. Clinical Genetics 2003 63 415-417. (doi:10.1034/j.1399-0004.2003.00070.x)

67 Kimber J, McLean BN, Prevett M \& Hammans SR. Allgrove or 4 'A' syndrome: an autosomal recessive syndrome causing multisystem neurological disease. Journal of Neurology, Neurosurgery and Psychiatry 200374 654-657. (doi:10.1136/jnnp.74.5.654)

68 Houlden H, Smith S, de Carvalho M, Blake J, Mathias C, Wood NW $\&$ Reilly MM. Clinical and genetic characterization of families with triple A (Allgrove) syndrome. Brain 2002125 2681-2690. (doi:10.1093/brain/awf270)

69 Goizet C, Catargi B, Tison F, Tullio-Pelet A, Hadj-Rabia S, Pujol F, Lagueny A, Lyonnet S \& Lacombe D. Progressive bulbospinal amyotrophy in triple A syndrome with AAAS gene mutation. Neurology 200226 962-965. (doi:10.1212/WNL.58.6.962)

70 Katsumata N, Hirose H, Kagami M \& Tanaka T. Analysis of the AAAS gene in a Japanese patient with triple A syndrome. Endocrine Journal 200249 49-53. (doi:10.1507/endocrj.49.49)

71 Schmittmann-Ohters K, Huebner A, Richter-Unruh A \& Hauffa BP. Clinical and novel molecular findings in a 6.8-year old Turkish boy with triple A syndrome. Hormone Research 200156 67-72. (doi:10.1159/000048093)

72 Sandrini F, Farmakidis C, Kirschner LS, Wu SM, Tullio-Pelet A, Lyonnet S, Metzger DL, Bourdony CJ, Tiosano D, Chan WY, et al. Spectrum of mutations of the AAAS gene in Allgrove syndrome: lack of mutations in six kindreds with isolated resistance to corticotropin. Journal of Clinical Endocrinology and Metabolism 200186 5433-5437. (doi:10.1210/jcem.86.11.8037)

73 Hallal C, Kieling CO, Nunes DL, Ferreira CT, Peterson G, Barros SG, Arruda CA, Fraga JC \& Goldani HA. Diagnosis, misdiagnosis, and associated diseases of achalasia in children and adolescents: a twelveyear single center experience. Pediatric Surgery International 201228 1211-1217. (doi:10.1007/s00383-012-3214-3)

74 Perry R, Kecha O, Paquette J, Huot C, Van Vliet G \& Deal C. Primary adrenal insufficiency in children: twenty years experience at the Sainte-Justine Hospital, Montreal. Journal of Clinical Endocrinology and Metabolism 200590 3243-3250. (doi:10.1210/jc.2004-0016) http://www.endocrineconnections.org DOI: 10.1530/EC-17-0255
() 2017 The authors Published by Bioscientifica Ltd

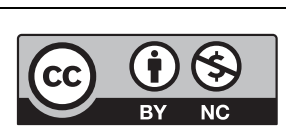

This work is licensed under a Creative Commons Attribution-NonCommercial 4.0 International License. 
75 Grant DB, Barnes ND, Dumic M, Ginalska-Malinowska M, Milla PJ, von Petrykowski W, Rowlatt RJ, Steendijk R, Wales JH \& Werder E. Neurological and adrenal dysfunction in the adrenal insufficiency/ alacrima/achalasia (3A) syndrome. Archives of Disease in Child 1993 68 779-782. (doi:10.1136/adc.68.6.779)

76 Huebner A, Kaindl AM, Knobeloch KP, Petzold H, Mann P \& Koehler K. The triple A syndrome is due to mutations in Aladin, a novel member of the nuclear pore complex. Endocrine Research 2004 30 891-899. (doi:10.1081/ERC-200044138)

77 Genin E, Tullio-Pelet A, Begeot F, Lyonnet F \& Abel L. Estimating the age of rare disease mutations: the example of triple-A syndrome. Journal of Medical Genetics 200441 445-449. (doi:10.1136/ jmg.2003.017962)

78 Heinrichs C, Tsigos C, Deschepper J, Drews R, Collu R, Dugardeyn C, Goyens P, Ghanem GE, Bosson D, Chrousos GP, et al. Familial adrenocorticotropin unresponsiveness associated with alacrima and achalasia: biochemical and molecular studies in two siblings with clinical heterogeneity. European Journal of Pediatrics 1995154 191-196. (doi:10.1007/BF01954269)

79 Cronshaw JM \& Matunis MJ. The nuclear pore complex protein ALADIN is mislocalized in triple A syndrome. PNAS $2003 \mathbf{1 0 0}$ 5823-5827. (doi:10.1073/pnas.1031047100)

80 Jühlen R, Landgraf D, Huebner A \& Koehler K. Identification of a novel putative interaction partner of the nucleoporin ALADIN. Biology Open 20165 1697-1705. (doi:10.1242/bio.021162)

81 Carvalhal S, Ribeiro SA, Arocena M, Kasciukovic T, Temme A, Koehler K, Huebner A \& Griffis ER. The nucleoporin ALADIN regulates Aurora A localization to ensure robust mitotic spindle formation. Molecular Biology of the Cell 201526 3424-3438. (doi:10.1091/mbc.E15-02-0113)

Received in final form 17 October 2017

Accepted 25 October 2017 http://www.endocrineconnections.org DOI: 10.1530/EC-17-0255
() 2017 The authors Published by Bioscientifica Ltd

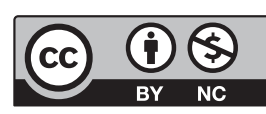

This work is licensed under a Creative Commons Attribution-NonCommercial 4.0 International License. 